\title{
Origin of embrittlement in metallic glasses
}

\author{
Glenn R. Garrett ${ }^{a, b}$, Marios D. Demetriou ${ }^{a, b}$, Maximilien E. Launey ${ }^{b}$, and William L. Johnson ${ }^{a, b, 1}$

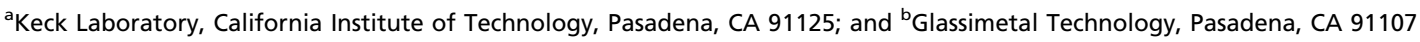 \\ Edited by Pablo G. Debenedetti, Princeton University, Princeton, NJ, and approved August 5, 2016 (received for review April 4, 2016 )
}

Owing to their glassy nature, metallic glasses demonstrate a toughness that is extremely sensitive to the frozen-in configurational state. This sensitivity gives rise to "annealing embrittlement," which is often severe and in many respects limits the technological advancement of these materials. Here, equilibrium configurations (i.e., "inherent states") of a metallic glass are established around the glass transition, and the configurational properties along with the planestrain fracture toughness are evaluated to associate the intrinsic glass toughness with the inherent state properties and identify the fundamental origin of embrittlement. The established correlations reveal a one-to-one correspondence between toughness and shear modulus continuous over a broad range of inherent states, suggesting that annealing embrittlement is controlled almost solely by an increasing resistance to shear flow. This annealing embrittlement sensitivity is shown to vary substantially between metallic glass compositions, and appears to correlate well with the fragility of the metallic glass.

ductility | amorphous metal | fracture toughness

U nlike conventional oxide glasses, metallic glasses can be considerably tougher, often approaching values typical of engineering metals. Specifically, the toughness of metallic glasses can vary from values as high as $150-200 \mathrm{MPa} \cdot \mathrm{m}^{1 / 2}(1,2)$, comparable to low-carbon steels, to as low as $2-3 \mathrm{MPa} \cdot \mathrm{m}^{1 / 2}(3,4)$, which is more typical of oxide glasses. But, like any glass, metallic glasses tend to embrittle when annealed around the glass transition, as evidenced by a measurable drop in their toughness and their capacity to deform plastically. This phenomenon, typically referred to as annealing embrittlement, has broad scientific and technological ramifications. From a technological perspective, annealing embrittlement is at least partly responsible for the large variability in toughness observed when the glass is quenched at different cooling rates (5-7), thereby limiting their mechanical performance and engineering reliability. From a physics perspective, the physical origin of annealing embrittlement is still a topic of debate and controversy that is far from being settled, as varying and contradictory theories have been proposed by various groups over the years.

$\mathrm{Wu}$ and Spaepen (8) made the first attempt to relate the toughness of the metallic glass to its structure. They postulated that annealing embrittlement is associated with a reduction in "free volume" in the glass atomic structure as it is relaxed at incrementally lower temperatures, degrading its capacity for plastic rearrangement and flow. Their concept has been adopted by several other groups (9-11). In recent years, an alternative concept has emerged linking the toughness of the metallic glass to its elastic constants, particularly to the ratio of the bulk to shear modulus (or equivalently to Poisson's ratio). This ratio is used to relate the resistances to cavitation and shear flow, respectively (12). Unlike free volume, the elastic constants of the glass are experimentally accessible so that this newer concept may be experimentally corroborated. Following this approach, one would expect annealing embrittlement to be associated with an increasing shear modulus, a decreasing bulk modulus, or a decreasing Poisson's ratio. It was indeed found that as the glass relaxes at temperatures around the glass transition, the drop in toughness is associated with changes in the elastic constants, and particularly the shear modulus $(13,14)$. More recently Kumar et al. (15) proposed yet one more theory, pointing to a sharp drop in bending ductility at a well-defined annealing temperature as evidence of a thermodynamic transition controlling annealing embrittlement. Lastly, the modeling work of Rycroft and Bouchbinder (16) is notable, where a shear transformation model of amorphous plasticity is coupled with a condition for cavitation to effectively simulate annealing embrittlement.

When a glass is relaxed near the glass transition for sufficiently long time, an equilibrium liquid configuration is attained, often referred to as an "inherent state." Quenching the equilibrium liquid freezes in such equilibrium configurations in the glass, where they give rise to properties (e.g., moduli, specific volume, etc.) that are unique and reversible. Thus, each of these properties is consistent with the definition of a state variable for thermodynamic equilibrium $(17,18)$. The fracture toughness of any material at the limit where it becomes size-independent (at the limit where the crack propagates in plane strain) is thought to be an intrinsic material property. It was recently shown that when the size requirements for plane-strain conditions and fracture toughness validity (according to ASTM standard E399) are met for a metallic glass, its fracture toughness value approaches a well-defined constant value (19). For an equilibrium glass configuration, one expects the "intrinsic" size-independent fracture toughness of a metallic glass to be consistent with the definition of an "inherent-state" property. As such, the intrinsic fracture toughness is expected to be uniquely associated with a specific equilibrium configuration, and to scale with other inherent state properties of that configuration (e.g., shear modulus, density, viscosity, etc.). A few studies have attempted to explore such fundamental relationships by correlating parameters that relate to fracture toughness (e.g., impact toughness or bending ductility) to inherent-state variables (e.g., configurational enthalpy or Poisson's ratio) $(10,15)$. However, samples in

\section{Significance}

Annealing embrittlement of metallic glasses is widely recognized as detrimental to their technological advancement, yet lacks fundamental understanding. Here, we identify a one-toone correspondence between fracture toughness and shear modulus, which points to a correlation between liquid fragility and annealing embrittlement sensitivity. From a scientific perspective, this finding provides a thermodynamic and structural origin of annealing embrittlement, revealing that lower potential energy glass states having higher flow barriers and atomic structures with higher degree of order will demonstrate a lower fracture toughness. From a technological perspective, this result suggests that fragile glass formers would be more prone to annealing embrittlement compared with stronger glass formers, and as such, their fracture toughness would be more sensitive to their processing history.

Author contributions: G.R.G., M.D.D., M.E.L., and W.L.J. designed research; G.R.G. performed research; G.R.G., M.D.D., M.E.L., and W.L.J. analyzed data; and G.R.G. and M.D.D. wrote the paper.

Conflict of interest statement: G.R.G., M.D.D., M.E.L., and W.L.J. (consultant) are currently employed by Glassimetal Technology Inc. All authors have an ownership interest in the company.

This article is a PNAS Direct Submission.

${ }^{1}$ To whom correspondence should be addressed. Email: wlj@caltech.edu.

This article contains supporting information online at www.pnas.org/lookup/suppl/doi:10. 1073/pnas.1610920113/-/DCSupplemental. 
those studies were either insufficiently relaxed to have attained thermodynamic equilibrium (10) or not sufficiently large to alleviate size effects on toughness (15). Thus, such fundamental relations may have been missed or obscured. Here, we seek to establish a fundamental correspondence between fracture toughness and inherent state that could reveal the underlying origin of embrittlement in metallic glasses. To ensure states of near-thermodynamic equilibrium, high-purity fully amorphous samples with size and geometry consistent with the E399 ASTM standard were produced and fully relaxed at well-defined temperatures in the equilibrium supercooled liquid regime.

Equilibrium configurational states of $\mathrm{Zr}_{35} \mathrm{Ti}_{30} \mathrm{Cu}_{8.25} \mathrm{Be}_{26.75}$ glass are carefully characterized at annealing temperatures near the glass transition for inherent-state properties and plane-strain fracture toughness. Fatigue-precracked rectangular beam samples were used to accurately evaluate the intrinsic fracture toughness. To establish near-thermodynamic equilibrium at a given temperature, each sample was annealed incrementally over multiple time steps followed by rapid quenching to room temperature. At each time step, the sound velocities and density $\rho$ were measured and the shear modulus $G$, bulk modulus $B$, and Poisson's ratio $v$ were calculated. An equilibrium state is assumed to be established when the modulus change with further annealing at constant time intervals is within the measurement error. Annealing temperatures from 40 degrees above/below the glass transition temperature of $\sim 573 \mathrm{~K}$ were considered to explore a sufficiently broad range of inherent states. Details on the measurements of the elastic constants and density are presented in Materials and Methods.

Fracture toughness tests were conducted in a three-point bending configuration using single-edge notched (precracked) beams in accordance with ASTM E399. Size requirements for both $K$-validity and plane-strain conditions were largely satisfied to rule out any effects of size and geometry on the intrinsic fracture toughness. For a linear-elastic $K_{\mathrm{IC}}$ measurement, the crack-tip plastic-zone size must be typically an order of magnitude smaller than $(i)$ the inplane dimensions of the crack length $a$ and the remaining uncracked ligament $b$ (a condition of small-scale yielding), and (ii) the out-of-plane specimen thickness dimension $B$ (a condition of plane strain); this is generally written as $a, b, B>2.5\left(K_{\mathrm{IC}} / \sigma_{\mathrm{y}}\right)^{2}$, where $\sigma_{\mathrm{y}}$ is the yield strength. Using the average measured $\sigma_{\mathrm{y}}$ of $1,700 \mathrm{MPa}$ (which was found not to vary appreciably between equilibrium states), the sample size $(a, b, B \approx 3.5 \mathrm{~mm})$ is sufficient to meet fracture-mechanics requirements for a valid $K_{\mathrm{IC}}$ measurement (i.e., for valid stress intensity $K$-dominated cracktip fields and/or for plane-strain constraint) if the measured toughness $K_{\mathrm{Q}}$ does not exceed $\sim 64 \mathrm{MPa} \cdot \mathrm{m}^{1 / 2}$. More details on the fracture toughness measurements can be found in Materials and Methods.

Processing and preparation of the samples was performed in a controlled manner to rule out any influence of extrinsic parameters such as crystallinity, oxygen, impurities, inclusions, or residual stresses on toughness. Specifically, to circumvent the adverse effects on toughness of either inclusions or crystallinity, the alloy ingots were prepared using high-purity elements with low oxygen content, alloyed under an ultrapure Ti-gettered inert atmosphere. The test samples were carefully inspected by X-ray diffraction (XRD) and differential scanning calorimetry to ensure the absence of detectable crystallinity. Long-range residual stresses arising in as-quenched samples, which may substantially influence toughness, were effectively eliminated by extensively grinding down cylindrical rods to obtain rectangular beams. The precracks were generated near the centerline of the original rods where residual stresses are expected to be near zero. Lastly, to obtain an accurate representation of the average configurational properties ahead of and in the plane of the crack tip, the ultrasound measurements were taken in the region just ahead of the crack tip and through the sample thickness. More details on the processing and preparation of samples can be found in Materials and Methods.

The measured $\rho, G, B$, and $\nu$ values associated with the relaxed states at temperatures $T_{\mathrm{R}}$ of $533,553,573,593$, and $613 \mathrm{~K}$ are listed in Table $1 . G$ is shown to decrease systematically with annealing temperature, as expected (20-22). The decrease in $G$ of $\sim 5 \%$ is considerably outside the measurement error. On the other hand, $B$ changes by just $\sim 0.3 \%$, roughly within the measurement error. Therefore, $G$ more closely tracks the transitions between inherent states compared with $B$, and is regarded here as the state variable that best characterizes the inherent state for each equilibrium configuration. This has also been verified by simulations, where it was determined that local atomic order in the glass structure strongly influences the transverse correlations of shear forces, which determine $G$, but does not significantly affect the atomic pressure correlations which determine $B(23)$. By plotting $G$ vs. $T_{\mathrm{R}}$ in Fig. $1 A$, an expected near-linear trend emerges $(17,21)$ with a slope of $-21.7 \mathrm{MPa} / \mathrm{K}$. Data for the recovered enthalpy $\Delta H$ associated with each relaxed state are listed in Table 1. $\Delta H$ is directly related to the configurational energy of the glass; the larger the $\Delta H$ value, the lower the configurational energy of the glass (21). In Fig. $1 B \Delta H$ is plotted against $T_{\mathrm{R}}$. Like $G, \Delta H$ decreases very systematically and consistently with $T_{\mathrm{R}}$ over a broad range. Fig. $1 A$ and $B$ points to a one-to-one correspondence between $G$ and $\Delta H(20)$, arising as $G$ and $\Delta H$ decrease correspondingly by relaxing to increasingly higher and shallower potential energy basins in the potential energy landscape.

The critical stress intensity $K_{\mathrm{Q}}$ obtained at each relaxed state is listed in Table $1 . K_{\mathrm{Q}}$ varies broadly from about $25 \mathrm{MPa} \cdot \mathrm{m}^{1 / 2}$ to about $75 \mathrm{MPa} \cdot \mathrm{m}^{1 / 2}$ over the $T_{\mathrm{R}}$ range considered. The $K_{\mathrm{Q}}$ values corresponding to annealing temperatures from 533 to $573 \mathrm{~K}$ are valid $K_{\mathrm{IC}}$ measurements. Whereas the $75-\mathrm{MPa} \cdot \mathrm{m}^{1 / 2}$ value does not strictly meet the sample size requirements for $K_{\mathrm{IC}}$ validity, the sample thickness and uncracked ligament are more than 5 times larger than the plastic zone size, and as such, any plane-stress and small-scale-yielding effects are expected to be too small to undermine the trends described below in any substantial way. When the $K_{\mathrm{IC}}$ values are compared with the moduli, a correlation between $K_{\mathrm{IC}}$ and $G$ is observed, but no clear correlation between $K_{\mathrm{IC}}$ and $B$ (outside the margin of measurement error) is apparent. A correlation between $K_{\mathrm{IC}}$ and $v$ is also evident, as suggested previously (9), but this correlation arises almost entirely from the $K_{\mathrm{IC}}$

\begin{tabular}{|c|c|c|c|c|c|c|c|}
\hline$T_{\mathrm{R}}, \mathrm{K}$ & $\rho, \mathrm{kg} / \mathrm{m}^{3}$ & $G, \mathrm{GPa}$ & $B, \mathrm{GPa}$ & $v_{1}-$ & $\Delta H, \mathrm{MJ} / \mathrm{m}^{3}$ & $K_{\mathrm{IC}}, \mathrm{MPa} \cdot \mathrm{m}^{1 / 2}$ & $L_{\text {rough, }} \mathrm{mm}$ \\
\hline 533 & 5,372 & $36.77 \pm 0.04$ & $105.0 \pm 0.33$ & 0.3433 & 57.0 & 24.7 & 0.266 \\
\hline 553 & 5,378 & $36.39 \pm 0.03$ & $105.8 \pm 0.18$ & 0.3457 & 37.8 & 25.8 & 0.315 \\
\hline 573 & 5,376 & $36.07 \pm 0.04$ & $105.8 \pm 0.27$ & 0.3469 & 29.8 & 35.9 & 0.566 \\
\hline 593 & 5,373 & $35.53 \pm 0.07$ & $105.6 \pm 0.17$ & 0.3488 & 12.9 & 60.9 & 0.899 \\
\hline 613 & 5,367 & $35.03 \pm 0.15$ & $105.4 \pm 0.30$ & 0.3505 & 0 & 74.4 & 1.28 \\
\hline
\end{tabular}




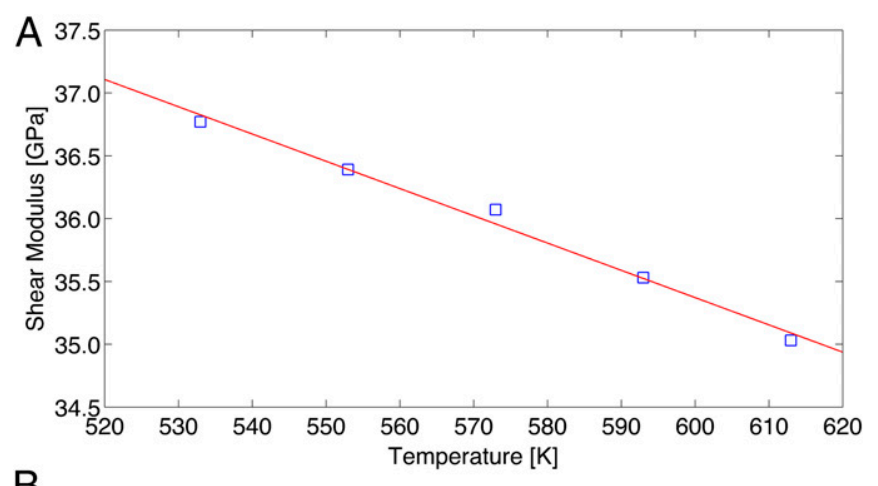

B

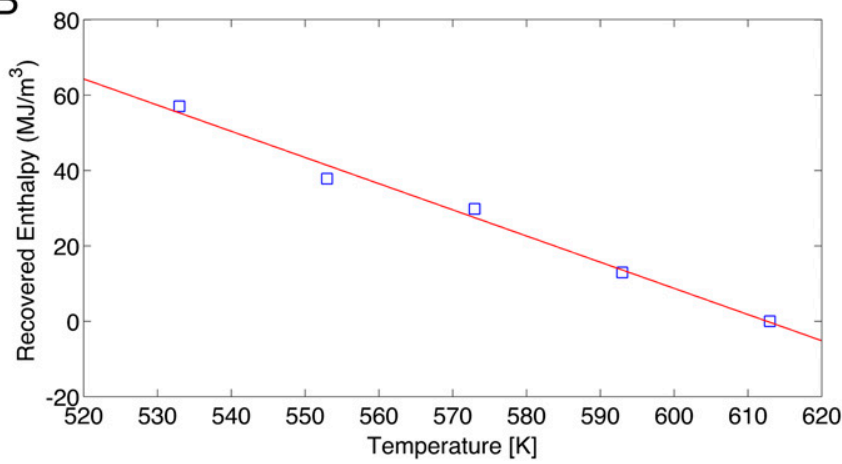

Fig. 1. (A) Shear modulus $G$ vs. relaxation temperature $T_{R},(B)$ recovered enthalpy $\Delta H$ vs. relaxation temperature $T_{R}$, for equilibrium configurational states of $\mathrm{Zr}_{35} \mathrm{Ti}_{30} \mathrm{Cu}_{8.25} \mathrm{Be}_{26.75}$ glass. Solid lines are linear fits through the data.

vs. $G$ correlation. Not surprisingly, a correlation between $K_{\mathrm{IC}}$ and $\Delta H$ is as robust as the $K_{\mathrm{IC}}$ vs. $G$ correlation. The strong $K_{\mathrm{IC}}$ vs. $G$ and $K_{\mathrm{IC}}$ vs. $\Delta H$ correlations reveal a sharply decreasing toughness as the glass is relaxed to increasingly lower and deeper potential energy basins.

To clarify this trend, the logarithm of $K_{\mathrm{IC}}$ is plotted against $G$ and $\Delta H$ in Fig. $2 A$ and $B$, respectively. A robust exponential relationship is established between $K_{\mathrm{IC}}$ and $G$ as

$$
\ln \left(\frac{K_{\mathrm{IC}}}{K_{\mathrm{IC}, \mathrm{o}}}\right)=-C G
$$

where $K_{\mathrm{IC}, \mathrm{o}}=4.7 \times 10^{12} \mathrm{MPa} \cdot \mathrm{m}^{1 / 2}$ is a characteristic fracture toughness scale corresponding to a hypothetical toughness of a zero shear modulus state (i.e., the limit of an ideal "incompressible" liquid), and $C=d \ln \left(K_{\mathrm{IC}} / K_{\mathrm{o}}\right) / d G=7.1 \times 10^{-10} \cdot \mathrm{Pa}^{-1}$ is the coefficient of the $K_{\mathrm{IC}}$ vs. $G$ exponential dependence. A similar exponential relation between $K_{\mathrm{IC}}$ and $\Delta H$ can likewise be obtained, but such relation is less meaningful as $\Delta H$ is a relative property with an arbitrary reference. Fig. $2 A$ and $B$ suggests that the "intrinsic" plane-strain fracture toughness $K_{\mathrm{IC}}$ follows exponentially decaying functions of $G$ and $\Delta H$. These relations appear to be continuous over a broad range of equilibrium configurational states of the glass, and no sharp drop in toughness at some "critical" annealing temperature of the type suggested by Kumar et al. (15) is evident.

To further investigate this apparent dependence of fracture toughness on the resistance to shear flow, we examined the fracture surface morphology. Scanning electron microscopy images of the fracture surfaces corresponding to the five relaxed states are shown in Fig. $3 A-E$. The fractographs are presented with the precrack surfaces aligned, to exemplify the extent of shear sliding activity ahead of the precrack. Sliding along shear bands ahead of the crack tip is the key mechanism of crack blunting and potential crack arrest in metallic glasses, and is understood to be the mechanistic origin of fracture toughness in these materials (1). Here, the extent of the shear sliding region ahead of the precrack, which forms the "plastic zone," is termed "rough zone width" and is designated by $L_{\text {rough }}$. The $L_{\text {rough }}$ value in each fractograph is approximated graphically by determining the level where steep ridges and deep valleys roughly merge. The $L_{\text {rough }}$ values are indicated in the fractographs of Fig. 3 and listed in Table 1 . As seen, $L_{\text {rough }}$ increases with increasing $T_{\mathrm{R}}$. A one-to-one correspondence between $K_{\mathrm{IC}}$ vs. $L_{\text {rough }}$ is evident from the data in Table 1, as first reported by Suh et al. (25). Such correspondence is shown graphically in Fig. $3 F$. Another characteristic fracture toughness scale arises from the $K_{\mathrm{IC}}$ vs. $L_{\text {rough }}$ dependence by extrapolation to $L_{\text {rough }}=0$, where $K_{\mathrm{IC}} \sim 10 \mathrm{MPa} \cdot \mathrm{m}^{1 / 2}$. This scale represents the opposite limit of $K_{\mathrm{IC} \text {,o }}$, characterizing the limit of fracture toughness where $G$ becomes large.

The correlations established here reveal that the plane-strain fracture toughness of samples equilibrated at different $T_{\mathrm{R}}$ is linked uniquely to properties characterizing the inherent state of the glass (e.g., $G$ and $\Delta H$ ). Analysis of the inherent states of a relaxed metallic glass (i.e., supercooled liquid states) based on potential energy landscape theory reveals that the isoconfigurational shear modulus $G$ is proportional to the activation barrier for plastic shear flow (i.e., configurational hopping between inherent-state basins), which scales directly with $\Delta H(17)$. As such, the exponential relation between $K_{\mathrm{IC}}$ and $G$ (and between $K_{\mathrm{IC}}$ and $\Delta H$ ) suggests that the process of crack blunting by shear banding ahead of the crack tip is consistent with hopping across activation flow barriers separating potential energy wells that define inherent states of the glass.

It is interesting to examine how this sensitivity to annealing embrittlement varies among various metallic glasses. One may quantify the annealing embrittlement sensitivity by a parameter

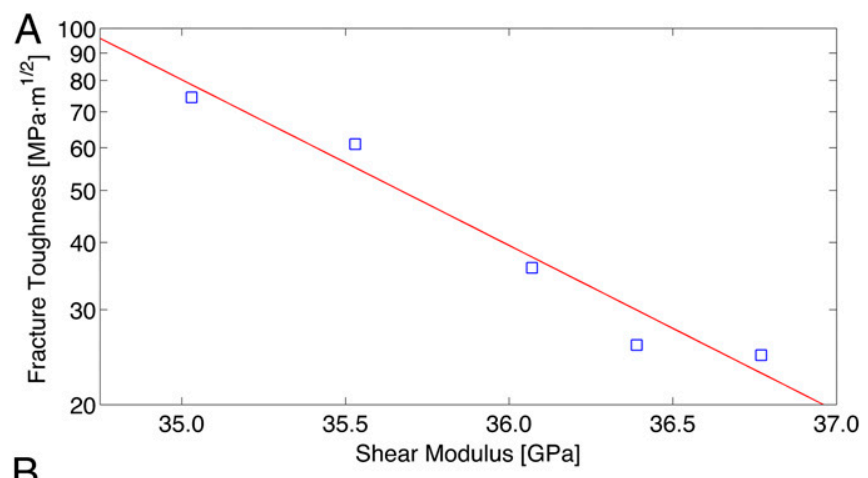

B

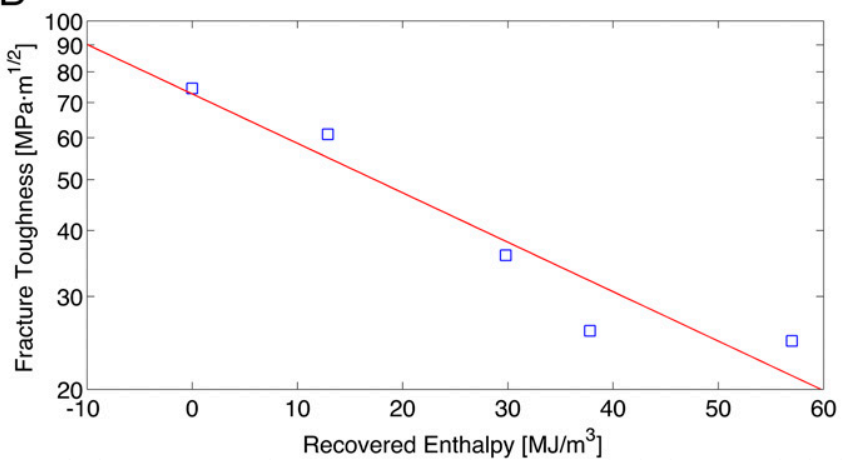

Fig. 2. (A) Logarithm of fracture toughness $K_{\mathrm{IC}}$ vs. shear modulus $G$, $(B)$ logarithm of fracture toughness $K_{\mathrm{IC}}$ vs. recovered enthalpy $\Delta H$, for equilibrium configurational states of $\mathrm{Zr}_{35} \mathrm{Ti}_{30} \mathrm{Cu}_{8.25} \mathrm{Be}_{26.75}$ glass. Solid lines are linear fits through the data. 


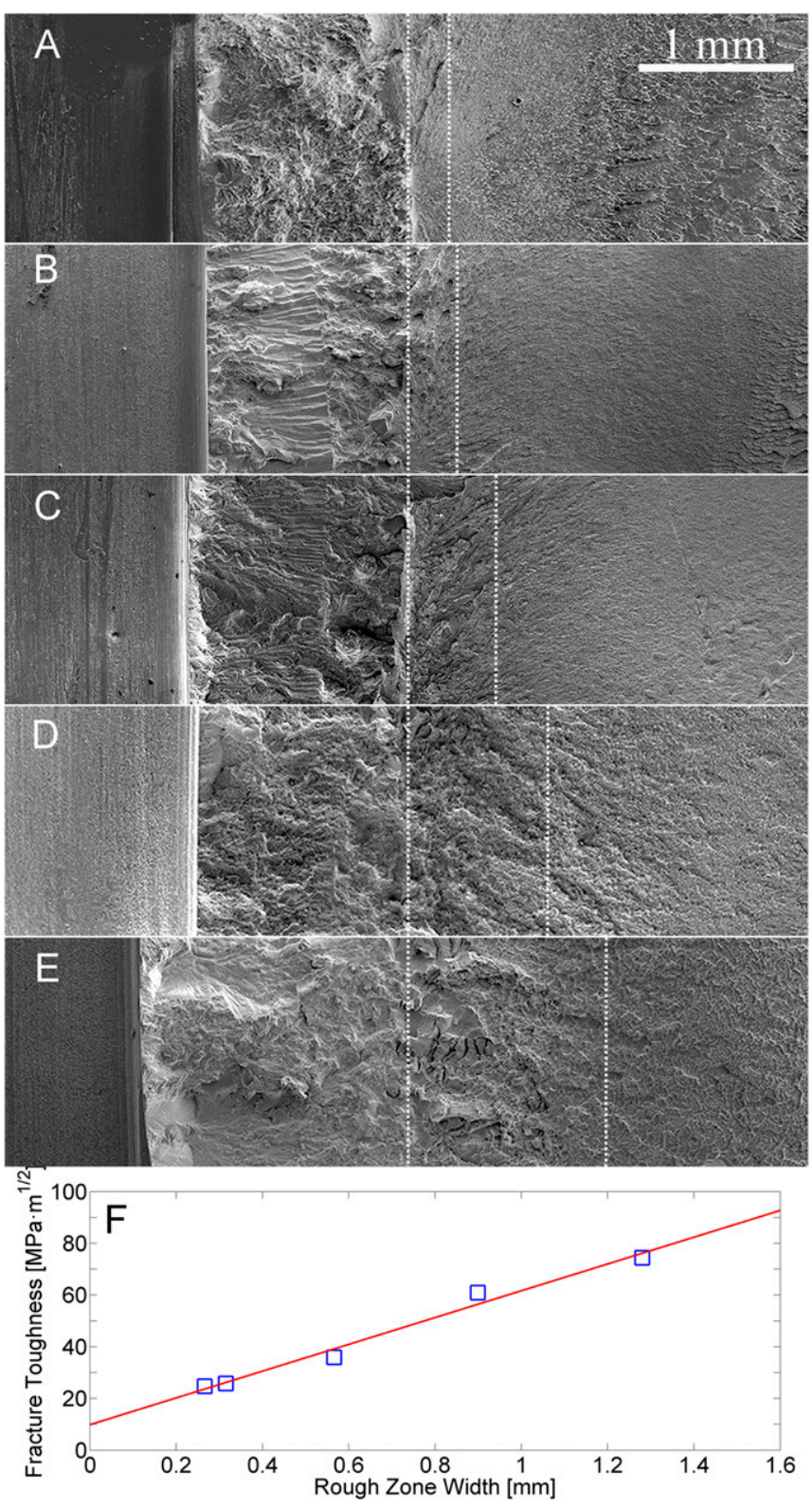

Fig. 3. Scanning electron micrographs of the fracture surfaces from fractured specimens associated with equilibrium states of $\mathrm{Zr}_{35} \mathrm{Ti}_{30} \mathrm{Cu}_{8.25} \mathrm{Be}_{26.75}$ metallic glass at various relaxation temperatures $T_{\mathrm{R}}$ : $(A) 533,(B) 553,(C) 573,(D) 593$, and $(E) 613 \mathrm{~K}$. The precrack surfaces in the fractographs are aligned and designated by dotted lines. The extent of the rough zone width $L_{\text {rough }}$ in each fractograph is also designated by a dotted line. $(F)$ Fracture toughness $K_{\mathrm{IC}}$ vs. rough zone width $L_{\text {rough }}$ for the conditions in $A-E$. The solid line is a linear fit through the data.

$F$ defined as the relative drop in fracture toughness $K_{\mathrm{IC}}$ with respect to a relative drop in relaxation temperature $T_{\mathrm{R}}$ :

$$
F=\frac{d \ln \left(K_{\mathrm{IC}} / K_{\mathrm{IC}, \mathrm{g}}\right)}{d\left(T_{\mathrm{R}} / T_{\mathrm{g}}\right)},
$$

where $K_{\mathrm{IC}, \mathrm{g}}$ is the fracture toughness of a glass relaxed at its glass transition temperature (i.e., at $T_{\mathrm{R}}=T_{\mathrm{g}}$ ). With this definition, the larger the value of $F$, the greater the sensitivity to annealing embrittlement. Data for $K_{\mathrm{IC}}$ at varying $T_{\mathrm{R}}$ are readily available in the present work for the $\mathrm{Zr}_{35} \mathrm{Ti}_{30} \mathrm{Cu}_{8.25} \mathrm{Be}_{26.75}$ glass; however, finding reliable data for other glasses in the literature is challenging. This is because most studies on fracture in the literature involve tests on metallic glasses that were either asquenched or not sufficiently relaxed. In the study of Kumar et al. (15), tests were performed on different metallic glass alloys that were sufficiently relaxed over a broad $T_{\mathrm{R}}$ range. Those tests were not actual fracture toughness tests but rather bending tests to failure. Nonetheless, one can estimate a critical Mode I stress intensity factor from the reported plastic strain to failure using the analytical expression of Conner et al. (26) (Supporting Information). Although a $K_{\mathrm{IC}}$ value estimated from such analysis is not strictly a plane-strain fracture toughness value, the drop of $K_{\mathrm{IC}}$ with decreasing $T_{\mathrm{R}}$ evaluated from such analysis is expected to be representative of the material's tendency to anneal embrittle.

In Fig. $4 A$, we plot $\ln \left(K_{\mathrm{IC}} / K_{\mathrm{IC}, \mathrm{g}}\right)$ vs. $T_{\mathrm{R}} / T_{\mathrm{g}}$ data for the $\mathrm{Zr}_{35} \mathrm{Ti}_{30} \mathrm{Cu}_{8.25} \mathrm{Be}_{26.75}$ glass gathered in the present work $\left(T_{\mathrm{g}}=573 \mathrm{~K}\right.$; $K_{\mathrm{IC}, \mathrm{g}}=41.5 \mathrm{MPa} \cdot \mathrm{m}^{1 / 2}$ ), along with data for $\mathrm{Pt}_{57.5} \mathrm{Ni}_{5.3} \mathrm{Cu}_{14.7} \mathrm{P}_{22.5}$ and $\mathrm{Zr}_{44} \mathrm{Ti}_{11} \mathrm{Cu}_{10} \mathrm{Ni}_{10} \mathrm{Be}_{25}$ reported by Kumar et al. (15) (Supporting Information, Figs. S1 and S2 and Table S1.). The plot reveals that the three metallic glasses exhibit very different propensities for annealing embrittlement, with $\mathrm{Pt}_{57.5} \mathrm{Ni}_{5.3} \mathrm{Cu}_{14.7} \mathrm{P}_{22.5}$ and $\mathrm{Zr}_{44} \mathrm{Ti}_{11} \mathrm{Cu}_{10} \mathrm{Ni}_{10} \mathrm{Be}_{25}$ demonstrating the highest and lowest annealing embrittlement sensitivity, respectively, and $\mathrm{Zr}_{35} \mathrm{Ti}_{30} \mathrm{Cu}_{8.25} \mathrm{Be}_{26.75}$ falling in between. One may notice that the order of annealing embrittlement sensitivity actually follows the order of the fragility of the three glasses. The fragility $m$, defined by Angell as the steepness of the viscosity temperature dependence at $T_{\mathrm{g}}(27)$, is often used as a parameter characterizing the potential energy landscape morphology of a glass/liquid. The value of the parameter $F$ evaluated as the fitting slope of the data in Fig. $4 A$ according to Eq. 2 is 11.7 for $\mathrm{Pt}_{57.5} \mathrm{Ni}_{5.3} \mathrm{Cu}_{14.7} \mathrm{P}_{22.5}, 8.5$ for $\mathrm{Zr}_{35} \mathrm{Ti}_{30} \mathrm{Cu}_{8.25} \mathrm{Be}_{26.75}$, and 2.7 for $\mathrm{Zr}_{44} \mathrm{Ti}_{11} \mathrm{Cu}_{10} \mathrm{Ni}_{10} \mathrm{Be}_{25}$. The
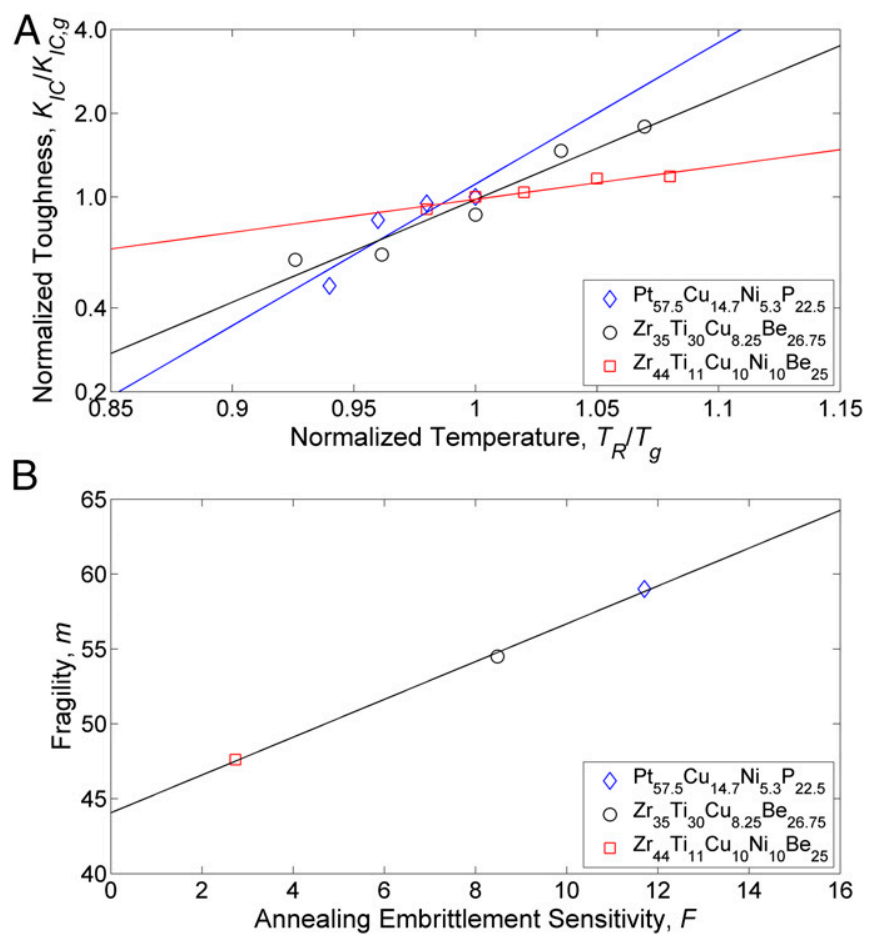

Fig. 4. (A) Logarithm of normalized toughness $K_{\mathrm{IC}} / K_{\mathrm{IC}, g}$ vs. normalized temperature $T_{\mathrm{R}} / T_{\mathrm{g}}$ for $\mathrm{Zr}_{35} \mathrm{Ti}_{30} \mathrm{Cu}_{8.25} \mathrm{Be}_{26.75}, \mathrm{Pt}_{57.5} \mathrm{Ni}_{5.3} \mathrm{Cu}_{14.7} \mathrm{P}_{22.5}$, and $\mathrm{Zr}_{44} \mathrm{Ti}_{11} \mathrm{Cu}_{10} \mathrm{Ni}_{10} \mathrm{Be}_{25}$. Solid lines are regressions through the data. (B) Fragility $m$ vs. tendency for annealing embrittlement $F$ for $\mathrm{Zr}_{35} \mathrm{Ti}_{30} \mathrm{Cu}_{8.25} \mathrm{Be}_{26.75}$, $\mathrm{Pt}_{57.5} \mathrm{Ni}_{5.3} \mathrm{Cu}_{14.7} \mathrm{P}_{22.5}$, and $\mathrm{Zr}_{44} \mathrm{Ti}_{11} \mathrm{Cu}_{10} \mathrm{Ni}_{10} \mathrm{Be}_{25}$. The line is a linear fit through the data. 
reported fragility $m$ is 59 for $\mathrm{Pt}_{57.5} \mathrm{Ni}_{5.3} \mathrm{Cu}_{14.7} \mathrm{P}_{22.5}, 54.5$ for $\mathrm{Zr}_{35} \mathrm{Ti}_{30} \mathrm{Cu}_{8.25} \mathrm{Be}_{26.75}$, and 47.6 for $\mathrm{Zr}_{44} \mathrm{Ti}_{11} \mathrm{Cu}_{10} \mathrm{Ni}_{10} \mathrm{Be}_{25}$ (28-30) (Materials and Methods). By plotting $F$ vs. $m$, as presented in Fig. $4 B$, a one-to-one correspondence between the annealing embrittlement sensitivity $F$ and fragility $m$ is suggested. With just three data points it may be premature to conclude that a "correlation" between $F$ and $m$ has been established, although from a thermodynamic perspective, such correlation is plausible. Fragility is understood to be controlled by the decrease of the isoconfigurational shear modulus $G$ with increasing potential energy (or temperature) $(18,20,21)$. Because a one-to-one correspondence between $K_{\mathrm{IC}}$ and $G$ is demonstrated here (Fig. 2 and Eq. 1), it is conceivable that fragility can be associated with the steepness of the $K_{\mathrm{IC}}$ drop with temperature, or equivalently with the annealing embrittlement sensitivity $F$. This outcome would have significant scientific and technological implications. From a scientific perspective, this result suggests a thermodynamic origin of annealing embrittlement, but also a structural one. In Angell's original conception, fragility quantifies how rapidly the "structure" (i.e., the local order) of an equilibrium liquid develops as the liquid cools toward $T_{\mathrm{g}}(27)$. Simulations verify that fragile glass formers indeed show a much more rapid rise of local order as the temperature decreases toward $T_{\mathrm{g}}$ (31). As such, the present result suggests that annealing embrittlement should be associated with the degree of order established in each equilibrium state at which the atomic structure of the glass is relaxed to. Considering the description recently proposed by Ma (32), one can relate annealing embrittlement to the distribution of inhomogeneous local structures (i.e., local motifs ordered to various degrees) established at each relaxed state, which varies from one equilibrium state to another. From a technological perspective, the present result suggests that more fragile glasses are more prone to embrittlement than stronger glasses. Specifically, it suggests that fragile glasses would tend to embrittle at low fictive temperatures and toughen at high fictive temperatures, whereas stronger glasses would have a more constant toughness with varying fictive temperature.

In conclusion, we demonstrate here that in the fully relaxed state of the metallic glass, the fracture resistance and shear flow resistance exhibit a one-to-one correspondence. Specifically, the present experiments reveal that the intrinsic toughness (i.e., the plane-strain fracture toughness) decays exponentially with the shear modulus and stored configurational enthalpy, and the decay functions are continuous over a broad range of equilibrium configurational states of the glass. A comparison of data for toughness vs. relaxation temperature among three metallic glass alloys reveals very different tendencies for annealing embrittlement. The data further suggest a potential correlation between annealing embrittlement sensitivity and the fragility of the equilibrium glass-forming liquid. Such a correlation can be rationalized by considering the temperature dependence of the barrier for shear flow. In summary, annealing embrittlement sensitivity, liquid fragility, and the temperature dependence of shear elasticity appear to have a common underlying origin.

\section{Materials and Methods}

Sample Preparation. Ingots of $\mathrm{Zr}_{35} \mathrm{Ti}_{30} \mathrm{Cu}_{8.25} \mathrm{Be}_{26.75}$ were prepared by weighing appropriate amounts of $\mathrm{Zr}$ (single crystal, $99.92 \%$ purity), Ti (single crystal, $99.99 \%$ purity), Cu (99.999\% purity), and Be (99.9\% purity). The in gots were alloyed by arc melting in a Ti-gettered argon atmosphere on a water-cooled copper hearth, and flipped at least four times to ensure chemical homogeneity. Rods $8 \mathrm{~mm}$ in diameter with lengths varying between 5 and $13 \mathrm{~cm}$ were produced by injection casting in a copper mold from the molten liquid state at $1,100{ }^{\circ} \mathrm{C}$. Controlled melt heating was performed with rf induction power under argon atmosphere, and with the melt temperature being monitored by an infrared pyrometer. The amorphous nature of all specimens was verified by XRD with $\mathrm{Cu} K \alpha$ radiation.
Mechanical Testing. Five single edge-notched bend $S E(B)$ specimens were machined out of cylindrical rods with thicknesses $B$ of $3.5 \mathrm{~mm}$ and widths $W$ of $7 \mathrm{~mm}$. The length $L$ of the specimens was slightly longer than the testing span length $S$ of $28 \mathrm{~mm}$. The specimen faces perpendicular to the crack were mirror polished with $0.02-\mu \mathrm{m}$ colloidal silica. All SE(B) specimens were fatigue precracked using a servo-hydraulic Materials Testing System in ambient air. Before fatigue precracking, notches having a length of $\sim 2 \mathrm{~mm}$ and a root radius of $125 \mu \mathrm{m}$ were created using a wire saw with $1-\mu \mathrm{m}$ diamond slurry. Fatigue precracks were created under load control using initial stress intensity ranges of $\Delta K=K_{\max }-K_{\min }$ of $\sim 11 \mathrm{MPa} \mathrm{m}^{1 / 2}$ at a constant frequency of $10 \mathrm{~Hz}$ (sine wave) with a load ratio $R=0.1$, where $R$ is the ratio of minimum to maximum applied load, $P_{\min } / P_{\max }$. The samples were fatigue precracked in multiple increments and the precrack length between increments was checked on both sides of the sample to ensure one straight precrack grew from the notch until the total crack length (including the notch length)-to-width ratio, a/W, was 0.5 . The lengths of the precracks were $\sim 1.5 \mathrm{~mm}$, well above the ASTM E399 standard requirements. Final values of $\Delta K$ during fatigue precracking never exceeded $60 \%$ of even the most brittle $K_{Q}$ result. Fracture toughness tests were performed in accordance with ASTM E399 under displacement control at a constant displacement rate of $0.3 \mathrm{~mm} / \mathrm{min}$. Load-displacement data were found to be linear to failure such that the value of $K_{Q}$ was calculated from the peak load at fracture. Compression testing was also performed using plane-parallel square beams with a side length of $\sim 3.5 \mathrm{~mm}$ and an aspect ratio of $\sim 2$ sectioned from each specimen postannealing. The stress-strain response was measured at a strain rate of $10^{-3} \cdot \mathrm{s}^{-1}$ in an Instron load frame, and the yield strength $\sigma_{y}$ was assessed. A yield strength of 1,700 \pm $20 \mathrm{MPa}$ was determined, which appears to be nearly independent of the relaxed state.

Annealing Experiments and Acoustic Measurements. Annealing of the precracked specimens was performed by sealing the specimen inside a quartz tube under an argon atmosphere, and annealing it in a furnace for sufficient time to relax the glass to a well-defined equilibrium liquid state. Subsequently, the specimens were directly quenched in room-temperature water by breaking the quartz tube immediately after immersing in water, to effectively retain the relaxed state established at the annealing temperature. The five specimens were annealed at the relaxation temperatures $T_{\mathrm{R}}$ of $533,553,573,593$, and $613 \mathrm{~K}$. Multiple annealing steps were performed at each temperature and the shear and longitudinal wave speeds along with the density were measured after each annealing step. XRD was also performed after each annealing step to verify that the specimens remained amorphous. Equilibration was assessed by monitoring the relaxation of the shear and longitudinal wave speeds. Equilibrium is assumed to be established when the wave speeds change by less than $0.2 \%$. The total annealing times at 533, 553, 573, 593, and $613 \mathrm{~K}$ were 15,000 , $520,170,41$, and $15 \mathrm{~min}$, respectively. Measurements for the density and elastic constants were performed on the precracked specimens before the fracture tests. The density was measured using the entire specimen by the Archimedes method, according to the ASTM standard C693-93. The roomtemperature shear and longitudinal wave speeds were measured in a zone immediately ahead of the precrack using the pulse-echo overlap technique with 25-MHz ultrasound transducers. Using the data for the elastic wave speeds and density $\rho$, the shear modulus $G$, bulk modulus $B$, and Poisson's ratio $v$ of the samples were calculated. Following annealing, the recovered enthalpy $\Delta H$ at $T_{\mathrm{g}}$ was assessed by differential scanning calorimetry by scanning a small segment from each annealed specimen using a Netzsch $404 \mathrm{C}$ calorimeter at a rate of $10 \mathrm{~K} / \mathrm{min}$. The recovered enthalpy of each specimen was calibrated in reference to the specimen that displayed the lowest value of $\Delta H$.

Fragility Evaluation. The viscosity of $\mathrm{Pt}_{57.5} \mathrm{Ni}_{5.3} \mathrm{Cu}_{14.7} \mathrm{P}_{22.5}$ was studied by Harmon et al. (28), who directly evaluated a fragility of $m=59$ by fitting the temperature-dependent viscosity using the cooperative shear model. The viscosity of $\mathrm{Zr}_{35} \mathrm{Ti}_{30} \mathrm{Cu}_{8.25} \mathrm{Be}_{26.75}$ was studied by Duan et al. (29) and that of $\mathrm{Zr}_{44} \mathrm{Ti}_{11} \mathrm{Cu}_{10} \mathrm{Ni}_{10} \mathrm{Be}_{25}$ by Waniuk et al. (30), and in both studies the VogelFulcher-Tamman (VFT) relation was used to fit the temperature-dependent viscosity. The VFT parameters and glass transition temperatures were reported to be $D=12.4, T_{\mathrm{o}}=422.6 \mathrm{~K}$, and $T_{\mathrm{g}}=578 \mathrm{~K}$ for $\mathrm{Zr}_{35} \mathrm{Ti}_{30} \mathrm{Cu}_{8.25} \mathrm{Be}_{26.75}$ (29) and $D=18.9, T_{\mathrm{o}}=412.5 \mathrm{~K}$, and $T_{\mathrm{g}}=623 \mathrm{~K}$ for $\mathrm{Zr}_{44} \mathrm{Ti}_{11} \mathrm{Cu}_{10} \mathrm{Ni}_{10} \mathrm{Be}_{25}$ (30). The fragility can be related to $D, T_{0}$, and $T_{g}$ as $m=D T_{o} T_{g} /\left[\ln (10)\left(T_{g}-T_{o}\right)^{2}\right]$, and can be calculated to be 54.5 for $\mathrm{Zr}_{35} \mathrm{Ti}_{30} \mathrm{Cu}_{8.25} \mathrm{Be}_{26.75}$ and 47.6 for $\mathrm{Zr}_{44} \mathrm{Ti}_{11} \mathrm{Cu}_{10} \mathrm{Ni}_{10} \mathrm{Be}_{25}$. 
ACKNOWLEDGMENTS. The authors acknowledge contributions from J.-Y. Suh, J. Monohan, and K. Fritz; valuable discussions with K. Samwer and U. Ramamurty; and express their gratitude to G. Ravichandran for providing the testing apparatus for the fatigue tests. This work

1. Demetriou MD, et al. (2011) A damage-tolerant glass. Nat Mater 10(2):123-128.

2. He Q, Shang JK, Ma E, Xu J (2012) Crack-resistance curve of a Zr-Ti-Cu-Al bulk metallic glass with extraordinary fracture toughness. Acta Mater 60(12):4940-4949.

3. Hess PA, Poon SJ, Shiflet GJ, Dauskardt RH (2005) Indentation fracture toughness of amorphous steel. J Mater Res 20(04):783-786.

4. Xi XK, et al. (2005) Fracture of brittle metallic glasses: Brittleness or plasticity. Phys Rev Lett 94(12):125510.

5. Gu XJ, Poon SJ, Shiflet GJ, Lewandowski JJ (2010) Compressive plasticity and toughness of a Ti-based bulk metallic glass. Acta Mater 58(5):1708-1720.

6. Gu XJ, Poon SJ, Shiflet GJ, Lewandowski JJ (2009) Ductile-to-brittle transition in a Ti-based bulk metallic glass. Scr Mater 60(11):1027-1030.

7. Zhu Z-D, Ma E, Xu J (2014) Elevating the fracture toughness of Cu49Hf42Al9 bulk metallic glass: Effects of cooling rate and frozen-in excess volume. Intermetallics $46(0)$ : 164-172.

8. Wu T-W, Spaepen F (1990) The relation between embrittlement and structural relaxation of an amorphous metal. Philos Mag B 61(4):739-750.

9. Ramamurty U, Lee ML, Basu J, Li Y (2002) Embrittlement of a bulk metallic glass due to low-temperature annealing. Scr Mater 47(2):107-111.

10. Murali P, Ramamurty U (2005) Embrittlement of a bulk metallic glass due to sub-Tg annealing. Acta Mater 53(5):1467-1478.

11. Launey ME, Busch R, Kruzic JJ (2008) Effects of free volume changes and residua stresses on the fatigue and fracture behavior of a $\mathrm{Zr}-\mathrm{Ti}-\mathrm{Ni}-\mathrm{Cu}-\mathrm{Be}$ bulk metallic glass. Acta Mater 56(3):500-510.

12. Lewandowski JJ, Wang WH, Greer AL (2005) Intrinsic plasticity or brittleness of metallic glasses. Philos Mag Lett 85(2):77-87.

13. Lewandowski JJ (2001) Effects of annealing and changes in stress state on fracture toughness of bulk metallic glass. Mater Trans 42(4):633-637.

14. Wang WH, et al. (2002) Stability of ZrTiCuNiBe bulk metallic glass upon isothermal annealing near the glass transition temperature. J Mater Res 17(06):1385-1389.

15. Kumar G, Neibecker P, Liu YH, Schroers J (2013) Critical fictive temperature for plasticity in metallic glasses. Nat Commun 4:1536.

16. Rycroft $\mathrm{CH}$, Bouchbinder E (2012) Fracture toughness of metallic glasses: Annealinginduced embrittlement. Phys Rev Lett 109(19):194301.

17. Johnson WL, Samwer K (2005) A universal criterion for plastic yielding of metallic glasses with a (T/Tg) 2/3 temperature dependence. Phys Rev Lett 95(19):195501.

18. Lind ML, Duan G, Johnson WL (2006) Isoconfigurational elastic constants and liquid fragility of a bulk metallic glass forming alloy. Phys Rev Lett 97(1):015501. was supported in part by the Materials Research Science and Engineering Center Program of the National Science Foundation under Grant DMR-0520565, and by the Office of Naval Research under Grant N00014-07-1-1115.

19. Gludovatz B, Naleway SE, Ritchie RO, Kruzic JJ (2014) Size-dependent fracture toughness of bulk metallic glasses. Acta Mater 70(0):198-207.

20. Demetriou MD, et al. (2006) Cooperative shear model for the rheology of glassforming metallic liquids. Phys Rev Lett 97(6):065502.

21. Johnson WL, Demetriou MD, Harmon JS, Lind ML, Samwer K (2007) Rheology and ultrasonic properties of metallic glass-forming liquids: A potential energy landscape perspective. MRS Bull 32(8):644-650.

22. Harmon JS, Demetriou MD, Johnson WL, Samwer K (2007) Anelastic to plastic transition in metallic glass-forming liquids. Phys Rev Lett 99(13):135502.

23. Cheng YQ, Ma E (2009) Configurational dependence of elastic modulus of metallic glass. Phys Rev B 80(6):064104

24. Garrett GR (2012) Study of the Origins of Toughness in Amorphous Metals (Caltech Library, Pasadena, CA).

25. Suh J-Y, Conner RD, Kim CP, Demetriou MD, Johnson WL (2010) Correlation between fracture surface morphology and toughness in Zr-based bulk metallic glasses. J Mater Res 25(05):982-990.

26. Conner R, Johnson W, Paton N, Nix W (2003) Shear bands and cracking of metallic glass plates in bending. J App/ Phys 94(2):904-911.

27. Angell CA (1995) Formation of glasses from liquids and biopolymers. Science 267(5206): 1924-1935.

28. Harmon JS, Demetriou MD, Johnson WL (2007) Rheology and ultrasonic properties of Pt57.5Ni5.3Cu14.7P22.5 liquid. Appl Phys Lett 90(17):171923.

29. Duan G, et al. (2007) Bulk metallic glass with benchmark thermoplastic processability. Adv Mater 19(23):4272.

30. Waniuk T, Schroers J, Johnson WL (2003) Timescales of crystallization and viscous flow of the bulk glass-forming Zr-Ti-Ni-Cu-Be alloys. Phys Rev B 67(18):184203.

31. Ding J, Cheng Y, Ma E (2013) Charge-transfer-enhanced prism-type local order in amorphous $\mathrm{Mg}_{65} \mathrm{Cu}_{25} \mathrm{Y}_{10}$ : Short-to-medium-range structural evolution underlying liquid fragility and heat capacity. Acta Mater 61(8):3130-3140.

32. Ma E (2015) Tuning order in disorder. Nat Mater 14(6):547-552.

33. Schroers J, Johnson WL (2004) Ductile bulk metallic glass. Phys Rev Lett 93(25):255506.

34. Lu J, Ravichandran G, Johnson W (2003) Deformation behavior of the $\mathrm{Zr}_{41.2} \mathrm{Ti}_{13.8} \mathrm{Cu}_{12.5} \mathrm{Ni}_{10} \mathrm{Be}_{22.5}$ bulk metallic glass over a wide range of strain-rates and temperatures. Acta Mater 51(12):3429-3443.

35. Wang RJ, Qin ZC, Li FY, Xie HS (1997) Elastic behaviors of bulk metallic glass $\mathrm{Zr}_{41.2} \mathrm{Ti}_{13.8} \mathrm{Cu}_{12.5} \mathrm{Ni}_{10} \mathrm{Be}_{22.5}$ investigated by using ultrasonic technique. Chin Phys Lett 14(12):920-923. 